\title{
An Analysis of the Factors That Enfluences Success of ICT Project Management
}

\author{
Iloka benneth chiemelie
}

\begin{abstract}
Information and Communication Technologies have since its inception become a very vital aspect of human life as a result of its power to make things easier. Integration of ICT in firms will expand the communication platform and make it easily accessible for the users, which will result to an increase in the flow of information within the system and increase troubleshooting solutions. The end product is an increase in productivity and profitability because the staffs within the system have been provided with a more open access to information and the necessary support in their job process. In any case, there have been recorded accounts of ICT failure in firms (for instance: Flyvbjerg, 2007), leading to suggestions that there is a need to understand the influence success of ICT programs in companies in order to boost the chances of such success. On that account, this paper was designed to understand these factors with respect to how they influence success or failure of ICT adoption and implementation - with special focus on ICT firms in Malaysia. The finding reveals similar accounts with earlier literature on the topic of project management in the sense that, TIME, SPECIFICATION and BUDGET were all determined to be of influential role in the success or failure of ICT projects. An additional area that was explored is to understanding of how level of happiness in the stakeholders can be used to measure the success or failure of an ICT project. The finding also revealed that the higher the stakeholders (management, project team and customers) are happy then the higher the success of the project and vice versa.

Key words: ICT Project, ICT firm, Success or Failure.
\end{abstract}

\section{Introduction}

There is no doubting the fact that the world is fast transforming into a technological hub since the $21^{\text {st }}$ century, with information and communication technologies leading this transforming through the enhancement of information availability, increase in access and advancing real-time communication (Flyvbjerg2007)This transformation provides benefits for both individuals and corporations and can easily be described as the most wonderful invention of human kind because it has helped to bridgegaps in communication. However, understanding the success and failure factor in ICT projects in ICT firms is not as easy as it sounds, and this is the main purpose of this research project. Basically, the failure factors exist in the absence of the success factors and the will focus more on understanding the success factors in order to enhance adoption of ICT across industries in Malaysia.

\section{Background}

Within the past decades, there has been a dramatic increase in the level of innovative activities in the modern economy (Achrol and Kotler, 1999). With respect to the previous stages that existed before what is obtainable now, there has been a significant change in the agent's behaviour. Particular reference can be made to great change in the environment patter and private initiative (Achrol and Kotler, 1999; Saw et al., 1999; Vilaseca and Torrent, 2005).

The notion presented from the above discussion is that firms have now become very important as both innovation agents and forces for training and entrepreneurship in the economy (Stells, 2001; Evangelista and Savona, 1998; Han et al., 1998). On that account, there is a need to understand how ICT can be used to enhance the performance of firms as it would allow for firms to understand how they can adopt such approaches.

In any case, it is important to understand that the management of ICT doesn't some at so much easy and as such determining the factors that influences the outcome of ICT adoption is very important for ensuring success in which practices. A number of literary sources have been developed to understand the success factors, much of which will be used in this research project. Such literatures come in the form of project planning studies which was presented by Bent Flyvbjerg's (2007) project parameters, J. Rodney Turner (1999) success factors and success criteria, and Meyer and Curley's (1995) project complexity factors.

\section{Problem Discussion}

There is a growing increase in the adoption of ICT in industries across the globe and this is causing an increase in the chances for failure as there is no set guidelines that will ensure success because of the differences in the management approaches adopted by the project managers. There is no doubting the fact that ICT managers are faced with numerous struggles in the process of managing ICT projects, even when they have the 
latest technological tools under their disposal and the necessary project management techniques required to ensure project success (Evan, 2008). Evan (2008) continued by stating that this is the problem plaguing ICT project managers worldwide. Bent Flyvbjerg (2007) presented an analysis of the infrastructure complexity in development of project management with respect to ICT. Following the advancement in technology, sophisticated information and communication devices are now pouring out across the globe and it is increasingly making the management of ICT very problematic (Szyliowicz and Goetz, 1995). For instance, as a result of the changes in ICT organization, there is an increase in the evolution of project managers that are inexperienced, disinterested and poorly informed (Barrett, 2008).

Even when the project managers have the needed expertise to ensure success, there is still this potential of failure as a result of other factors or unexpected factors that cannot be easily managed. While failure sounds like an issue that should not be a concern to people in the field of project management, there is a need to understand that the implementation of ICT projects comes at a very high cost in most cases and failure will mean an increase in loss of value in terms of the incurred expenses.

\section{Research Purpose}

Basically, the purpose of this research has been expressed to some extent in the research title. The title clearly states that the research is designed to evaluate the factors that influence success or failure of project management in firms and this is exactly the purpose of the research. Discussions presented in the above research background have shade light on the understanding that the implementation of an ICT project comes with high difficulties in terms of management as the increasing innovation and advancement of technologies in this area now means that managers need new skills for new innovative streams in order to be successful in the field and the implication is a subsequent increase in the chances of failure. While failure can occur at a high rate, it is also important to understand that success also have a high chance of occurring as long as the necessary approaches are taken into consideration. As such, this research project aims to understand the factors that influence both success and failure in order to eliminate the failure relates issues while advancing the success factors for a better ICT management success.

\section{Research Questions}

In order to achieve the purpose of this research, a number of questions will be asked in line with the research topic and they include:

What are the factors that influence success or failure in ICT management? - This is the first question to be address and it is at the core of the research purpose. Before any evaluation can be conducted, there is a need to understand the factors that will be evaluated and this questions aims to do so by understanding the factors that influences failure or success in the case of ICT management.

To what extent do these influences affect ICT management? - With the factors identified, the next case is to understand the extent of such influence on ICT management. Measuring the extent of influence is important as it would help to understand the how the factors can be enhanced or mitigated and the best strategy to ensure such.

How can these factors be enhanced or mitigated? - With the influence now measured, the next is to understand how the factors that influence ICT management can either be enhanced or mitigated.

\section{Research Scope}

The scope of this research is centred on ICT management. The field of information and communication technology is very broad and so is the same with management for both business and non-business areas. Combining these two broad fields together to form one topic is expected to be very difficult, but the topic narrows down the research scope to ICT management in firms. On that account, the research project will focus specifically on the management of ICT in Malaysian ICT firms by evaluating the factors that influences success or failure in that area.

\section{Motivation}

The reason for undertaking this research is to understand the factors that influence success or failure in ICT management and how the negative factors can be improved. Although they are numerous models existing with respect to the research topic, the narrowing down of the models for this research project created a suitablechannel for a direct understanding of how effective these models are. The motivation for this research is pinned by the understanding that discussing the factors that influence success and failure of ICT will help to understand the best way that ICT programs can be implemented successful in organizations. 


\section{Research Limittattion}

From the discussion presented above in terms of the purpose of this research and the expected outcome from the research process, there is no denying the fact that the research project is very significant and will be of numerous benefits in the field of ICT and management. This is because by highlighting the factors that influences success or failure in this area, the thesis report will provide managers with the right key to ensure success as they will be better positioned with the understand gained to undertake their job description in the sense that it would serve as a clear guideline on the does and don't in the management of ICT projects.

However, the research faces severallimitations and the limitationsare foundin the scope of study. While the research aims to identify the factors that influence success or failure, the thesis report is not designed to understand the concepts, steps or the best ways for managing ICT project. On that account, this limits the understanding of how the actual issues identified can be limited and how the success factors can be enhanced in order to turnout a better ICT management process in the industry.

\section{Introduction}

\section{Literature Review}

From the first chapter and the theoretical background, it was made known that the second chapter will deal on understanding the theories that surrounds the research topic in order to create a better background for fulfilling the purpose of this research and achieving set research objectives. This is exactly what will be undertaken in this chapter as it will present an overview of relevant theories that surround the research topic.

\section{Understanding What Ict Project Is All About}

Pekka (2008) presented a clear view on what ICT project is all about and his view is that information and telecommunication technology (ICT) projects are usually the outcome gained from the development and installation of software products, but not all ICT projects are purely about the development and installation of networks. In term of the construction industry with special reference to building construction, it is very easy to identify the different types of projects based on the differences in terms of their differing natures of work, but this is not the same with ICT project. For instance, it can be seen that the needed construction feature in the building of a new home, renovation and replacement of damaged homes are different because they require different construction features. This is the same with ICT project; there are differences in functions from the beginning of the project right to the installation and after installation maintenance, which makes it very much viable to understand these differences in order to create the right base for analysing how the necessary solutions will be provided.

It was also noted by Pekka (2008) that traditionally, the management of ICT projects involves the manager having to carefully plan the tasks involves, scope, estimate, schedule, resources, and the control measures that will be applied throughout the project, which will also include some certain level of hybrid in terms of the requirement and having such plan done in a way that is based on work tasks. On that account, it becomes very much evident that there will be some certain level of difficult associated in the management of ICT projects because of the subsequent difficulties involves in the estimation and schedule in order to ensure a quick start to slip. In fact, there are evidence from the study of over 500 completed contracts that shows that once a project has reached about 15-20\% level of completion (Christensen, 1993), the following abide:

1. The absolute overrun at the time of completion will not be less than the overrun during the start date; and

2. The percentage overrun at completion will be higher than the percentage overrun at the start date.

Even at this point, there is still no clear definition of what project management is all about, but the scope of such as it relates to this thesis report will be based on the often quotes of Tom DeMarco: that you can't imagine what you can't measure (DeMarco, 1995). As such, project management is defined as the coordination of the project process, beginning from the development of the ICT to the installation, and also including the after installation services that are provided for the maintenance of the project. As such, project management in ICT is very unique in the sense that it comes with a number of features that must be individually aligned together in order to ensure that the project process becomes a success and that the final project actually meets the needs it was designed for.

\section{The Adoption Of Ict In A Business Context}

There have been fostered transformations in all levels of business as a result of the increasing adoption of ICT in the business process. The increasing use of ICT with the adoption of a business culture that is developed around such and oriented to the market has increased the encouragement for development of a new organizational, productive and strategic management models (Song et al., 1997). This plays a contributory role in the establishment of an increase in flexibility within organizational structures, an enhancement efficiency and 
effectiveness in the productive processes and strategic models that are geared towards the generation and adoption of information and knowledge (Grönroos, 2000; Tzokas and Saren, 1997; Vorhies et al., 1999).

The increase in globalization and internationalization of firms has led to a subsequent changes in the business environment, and these changes now means an increase in the awareness of firms not only for the situations it faces in its social agent, but also with respect to the understanding of the environment issues facing its business (Pekka, 2008). On that account, there have been experiments of organizational culture resulting in key changes in the form of organizational values, missions and visions, and the strategic objectives of the organization behind modified to meet the integration of ICT as part of the organizational design (Dyer and Nebeoka, 2000; Vorhies et al., 1999).

Although the need to adopt ICT management in the business process is something that has increased in the organizational design, it must be understood that differences in the organizational design means a subsequent differences in terms of how ICT is being adopted in the organizational setting. Wei and Morgan (2004) described this as being either an internal or external adoption. In terms of the internal adoption, it comes as a form of support for the productive segment of the business, with the main purpose of enhancing the production process of the company by providing needed technical support and expertise that will be used to reduce the delays in service delivery and increase quality of the products and services delivered. The external adoption comes mainly in the form of a support for enriching the customers' satisfaction gained from using the product or service. It is from this experience that the customer gains a better understanding of the who project benefits and utilizes it to the utmost satisfaction and for the sole purpose of meeting the needs it has been designed to fulfil.

\section{Determinants Of Success Or Failure In Ict Projects}

For any ICT project to be guided towards high success there is a need for the manager to understand the criteria by which success in the project process is measured, and fulfilling these criteria should be the main priority of the project manager.

Right from the 1960s, there have been the emergence of authors (e.g. Ingram, 2000; Wright, 1997; Turner, 1993) who have steadily accepts that success in project management is a product of three constraints in the form of time, cost and specification, and this has for long been the standard for measurement of success in project management. The assumption led down by this is that the completion of projects in time will ensure that the project is opened as due, and success should come in the form of the budget not being overrun and the project satisfying the specifications placed down by the company's investors - of which any variation in this means that the project is a failure (Ingram, 2000; Wright, 1997; Turner, 1993).

In any case, it must be understood that ICT project is different from the normal projects and determining whether it is a success or failure is a much more complex thing to do (Belassi\&Tukel, 1996). This has even led to some authors arguing that ICT projects cannot be seen as having to either completely failed or completely successful (Wateridge, 1998). On the same hand, there are different parties involved (for instance, management, project team, users, supporters, stakeholders etc.) and this can led to the perception of the project success in different ways (Pinto \&Slevin, 1989). Even in cases where the individuals come from the same party, variations can also occur in terms of their opinions because different individuals view success different and have their own set of criteria for which the project success is measures and these criteria can be quite subjective in nature (Fowler \& Walsh, 1999). Additionally, it is not all the criteria that can be measured at the same time. Some of these criteria can be assessed only on the long run basis following the determination of the project, and good examples will be in the form of the financial or commercial success of an ICT implementation (Wateridge, 1996).

Koen\&Koen (2005) conducted a similar research in order to understand the factors that influence success in ICT project management. While the factors are not certain as compared with other conventional project, there are still some predetermined factors that influences success as highlighted by the authors and they include:

Time - time is also very important in terms of determining the potential for success in ICT project management as described by Koen\&Koen (2005) and this is based on the understand that it is the direct description of whether a project will be used for the purpose of what it is designed for and the investment realized before competition enters the market. The lack of on-time delivery in the project process comes with numerous negative influences in the form of the project not being commission as proposed on time and the chances of the high returns decreased especially considering the fact that ICT projects can easily be duplicated. As such, speedy delivery of the project is a direct measure of success.

In ICT project management, time also determine the level of success of failure and this is because if much time is allocated to a specific project, the chances of success will be increased because there will be a lot of time for the project to be completed based on specifications and with high quality. However, poor allocation 
of time increases chances for failure because the project will be rushed and minor errors or even major ones might exist following the successful completion of the project.

Within budget-Koen\&Koen (2005) noted that besides time, there is also the need to reduce risk by ensuring that the investment used to make an ICT project a success fall well in line with the budget made for that project. The inability of the project to be completed within the budget provided will mean an increase in budget and such result in reduction of the profit to be generated from the project completion and the project can then be described as being unsuccessful because the budget has been exceeded and risk increased in the process.

There is no doubting the fact that budget influences success or failure in ICT project management. Basically, budget plays significant role in all forms of project management and as such it is important to understand the budget factors and conduct the project in such a way that budget provided are sufficient enough to ensure completion and success. For every ICT project, the higher the budget, the higher the chances of success and vice versa.

To specification - for every project, there are certain specification that the project is designed to meet and it is based on the understanding that meeting such specification is the only way the project can have a better chance of meeting the needs it has been designed for. As such, this is also a direct measured of success or failure in the project process.

For every project, there is a reason for its design and these reasons normally serve as the bedrock from which the project is designed. On that note, success is enhanced when the specifications are very clear and reduced in complex or sophisticated specification. This is because clear specification will ensure that the project is easily undertaken as the project manager will understand what is expected from the project, while an unclear specification will mean that the project management might be confused in the overall project design which will increase chances of failure. As such, the clearer the specification, the higher the chances of success and vice versa.

Stakeholders' happiness - the stakeholder in ICT project include the management, staffs, and end users (Koen\&Koen, 2005). The level of happiness gained by these stakeholders is used as a direct measure of the success of an ICT project management and this is because success of the project will make them happy. When a project is successful, it means that the specification set by the management has been meeting, the employees have been dully paid and the users are benefiting from the project. As such, the higher the level of happiness exhibited by the stakeholders, the higher the success of the project.

As such, these factors identified will be loaded into the primary research in order to understand how they influence success or failure of ICT project. At the end, the findings will be used to either support or disprove the theories contained in this review of literatures and define a better understanding of how success can be enhanced and failure reduced in ICT project management.

\section{Introduction}

\section{Research Methodology}

Continuing from the foundation laid down by the second chapter as contained above, this research will proceed with other contents as discussed in the chapter one. From the first chapter, it was made known that this section aims to described how the primary research will be conducted, highlighting the purpose, methodology and approaches for the primary research.

\section{Research purpose}

Earlier on, the objective s of the research were stated to be to gain an understanding of the factors that influences success or failure in ICT project and determine the level of influence yielded by these factors with respect to what makes them yield such influences, and how they can either be reduced or enhanced (depending on whether the influence is positive or negative). This purpose will be loaded into the questionnaire to include an understanding of what the respondents think about ICT projects as it related to what they think are the factors that influences success or failure. This understanding will be used to acquire a more view of their opinion in relation to how they think these factors can either be enhanced or reduced with respect to increasing the positive influence which reducing the negative influence.

\section{Research Method}

The strategy for this research will be an exploratory research method which is conducted in the form of an in-depth study with the responders. The responders comprises of both students in the ICT department and staffs form ICT firms in Malaysia and all of the respondents account to a total of 100 responses. Exploratory research is a form of research which is designed to explore different aspects of the topic being studies. The word 
"exploratory" implies that it doesn't focus on any general objective as to meeting some specified points, but instead it is diverse in its approach to review by offering the opportunity for researchers to understand different aspects of the study section and explore other areas that might have a direct influence on finding from the research.

In-depth study on the other hand is a form of interviewing in which the research chats with the responder one-on-one in order to understanding their views about the projected changes from the research hypotheses. Such a close discussion will be enhanced by adopting necessary strategies to ensure that the responders feel at ease and peace with the researcher in order to make them comfortable with the research process and also enhance their possibilities of contributing to the research process positively. Such approach will include a discussion of the importance of the study, which will then persuade them to contribute significantly towards the research process.

The main reason for adopting an in-depth form of exploratory research strategy in this qualitative research is because the topic being reviewed doesn't have a common ground for judgement. From the review of literature as contained above, it was made known that there are differences in view with respect to what people from different fields think influences success or failure or a research. While time, within budget and meeting specifications are generally accepted as the criteria for measuring success or failure in project, there are new developments that have linked such measurement with happiness of stakeholders. Others think that it can also be linked to the level of financial and commercial success in terms of how the new project has been sold in the market and the revenue (profit) generated from such sales.

\section{Research Approach}

The approach for this research is qualitative approach. In accordance with Sage publications (2013), the qualitative approach to research is a unique background that is used to foster precise ways of asking questions and particular ways for thinking through problems. Common questions that are asked in qualitative researches are designed to provide answers as to how, why and what factors that influences the issue being review. Qualitative research is a very exciting landscape that is interdisciplinary in nature and comprises of wide perspective and practices used for generating knowledge. Researches from all across filed in the social and behavioural use adopts qualitative research - and it is important to understand that the context of this research project is also based on social and behavioural studies. Additionally, the research process involved in qualitative is usually given the centre stage and this means that the searcher have high potential of focusing on the subject matter in review and applying all necessary approaches to ensure that the research is usually gathered towards achieving set objectives through set parameters that can be used to measure the success of the research process.

Basically the essence of qualitative research is built around the tyranny of numbers it has abandoned for the purpose of creating enigma in words. instead of creating a "Yes" or "No " approach to research methodology, qualitative research allows the audience to offer opinion based on a clear definition of what they perceive to be the problem and how they wish to solve the problem in the long run. It is often seen as being rooted in the non-tangible domain, which is based on experimental and intuitive researches studies that are fundamental in natures.

In accordance with Hiat (1986), p, 737), qualitative works are in constant and dynamic flux, but in essence it is moving towards some of the end-point in modern evolutionary way, numerous efforts have been made by the different researchers in order to establish a concrete meaning on the qualitative dimensions and it also serve as an integrative function from which the researchers develop an absolute understanding in the context of the subject being studied.

The main reason for choosing qualitative research is because the review of literature has shown that differences exist in terms of how the factors that influences success or failure is perceived amongst stakeholders in relation to ICT project. As such, providing a direct question will not allow respondents to usher in their own perceived understanding and view with respect to the research question, while expanding the view as is experienced in qualitative research will provide the needed space for an expanded response that will allow the researcher to gain a clear view of the main factors that yield influence on either the success or failure of ICT projects.

\section{Research Strategy}

For this research, the adopted strategy is an intercept-based study. This implies that the respondents will be intercepted at their best available time with the questionnaire for them to provide their response on the questions. Since this is a firm specific research in the sense that is the designed to understand the factors that influences success or failure of ICT projects with respect to firm based view (stakeholders), the study will be conducted in ICT firms with their employees. The idea of choosing ICT firm is because the respondents (staffs in the firm) will be much familiar with the research question as compared with other without any ICT experience. As such, it is much easier for the needed information to be gathered and the finding easily analysed. 
Additionally, the fact that the respondents are very much aware of the question also means that the reliability of the study is enhanced in the sense that their response is much reliable when compared with respondents without such ICT background.

\section{Survey}

The survey will be a 20 questions based questionnaire that will be measured with a 5-point Likert's rating scale. The idea is to expand the question to cover numerous wings in the field of study and allow for a more detailed analysis of the finding to be gained from the study. Additionally, the 5-point rating (in the region of totally disagree (1) to totally agree (5)) will allow for a more precise response as compared with the "Yes" or "No" platform that tends to force respondents into accepting a specific response.

\section{Sample Selection}

A total of 100 respondents were selected from different ICT firms in Selangor and from the ICT department of Stamford College, Malaysia and the ICT students of the same College. The firms used in this case include Dominant Palace SdnBhd and Subharma IT training centre. The survey was conducted in June 2013, which makes it very current and reliable in the sense that the firms used for the survey can be contacted and enquiries made in relation to the study. The rule of thumb stated that in order for a research to be considered viable, the respondents must be at least twice the number of questions asked. On that account, it can be seen that this research is very much viable and this is based on the understanding that the respondents are 5 times bigger than the questions asked, which makes it likely that the end product will be positive in terms of enhanced quality, validity and reliability of the finding.

\section{Data Collection}

Once the questionnaire has been designed, the next move is to gather the necessary data that will be used to prove the research objectives. This will be done in two different forms. The first is the internal data gathering which will involve gathering data from the chosen respondents in the school. The second will be the external data gathering, which will involve gathering data from the respective ICT firms that have been chosen across Selangor. The internal data gathering will be done an school day when all the ICT students will be present in order to ensure that the chances of gathering adequate data is enhanced. The external data gathering will however be undertaken within agreed time with the ICT firm. No matter the form of data gathering, all data that will be gathered will be done within a space of 2 weeks ( 10 working days) in order to allow adequate time for data analyses and re-gathering of data in cases where the gathered data is not considered sufficient or reliable. Additionally, it would allocate adequate time for data analysis which is very important in order to ensure that the whole research is completed within the stipulated time frame.

\section{Data Analysis}

All the gathered data will be analysed with SPSS statistical analysis tool. This is the most commonly adopted tool for analysis in primary research and it has been proven to be reliable and effective in terms of analysing data gathered from a research. This main focus will be on understanding the descriptive variables as a means of measuring the level of influence these variables yield.

\section{Research Quality Criteria}

Considering the potential influence that findings from this research will have in real-life application, there is a need for the research to ensure that data gathering and analysis are done in with a higher degree of quality ensured. This is because the research will only be able to impact positively in the field of study under such circumstances and extra measures were taken to ensure that quality is the philosophy of the research as can be seen from the analysis below (test of validity and reliability).

\section{Validity and Reliability}

The test of validity was done by computing a descriptive analysis of the gathered data in order to ensure that none of the gathered data is missing or poorly imputed, while the test of reliability was conducted with the Cronbach's Alpha analysis. 


\section{Validity}

Table 3.1: Descriptive Statistics of gathered data

\begin{tabular}{|c|c|c|c|c|c|}
\hline & $\mathrm{N}$ & Minimum & Maximum & Mean & Std. Deviation \\
\hline Employment & 100 & 1.00 & 2.00 & 1.7000 & .46057 \\
\hline Gender & 100 & 1.00 & 2.00 & 1.3400 & .47610 \\
\hline Age & 100 & 1.00 & 3.00 & 1.8100 & .48607 \\
\hline $\begin{array}{l}\text { What type of ICT Company do you } \\
\text { work with? }\end{array}$ & 100 & 1.00 & 4.00 & 3.3000 & 1.06837 \\
\hline Primary role in the company & 100 & 1.00 & 3.00 & 2.0300 & .79715 \\
\hline Currently Undertaking any project? & 100 & 1.00 & 2.00 & 1.1500 & .35887 \\
\hline $\begin{array}{l}\text { What ICT proejct are you familiar } \\
\text { with? }\end{array}$ & 100 & 1.00 & 4.00 & 1.6500 & .98857 \\
\hline $\begin{array}{l}\text { How long have you worked in ICT } \\
\text { projects? }\end{array}$ & 100 & 1.00 & 4.00 & 2.6100 & 1.17975 \\
\hline $\begin{array}{l}\text { How long has your company been } \\
\text { using ICT for business process? }\end{array}$ & 100 & 2.00 & 4.00 & 3.5300 & .75819 \\
\hline ICT Projects completed & 100 & 1.00 & 4.00 & 3.1500 & 1.07661 \\
\hline $\begin{array}{l}\text { An ICT project is considered a } \\
\text { success if it is completed within } \\
\text { designated time. }\end{array}$ & 100 & 1.00 & 5.00 & 4.2300 & 1.18794 \\
\hline $\begin{array}{l}\text { An ICT project is considered a } \\
\text { failure if it is not completed within } \\
\text { designated time }\end{array}$ & 100 & 1.00 & 5.00 & 4.0200 & 1.26315 \\
\hline $\begin{array}{l}\text { Time management is very crucial in } \\
\text { ICT project management because it } \\
\text { can determine the level of success } \\
\text { to be achieved from the project. }\end{array}$ & 100 & 1.00 & 5.00 & 4.2200 & 1.05006 \\
\hline $\begin{array}{l}\text { An ICT project is considered a } \\
\text { success if completed within the } \\
\text { stipulated budget }\end{array}$ & 100 & 1.00 & 5.00 & 4.0200 & 1.29474 \\
\hline $\begin{array}{l}\text { An ICT project is considered a } \\
\text { failure if the stipulated budget is not } \\
\text { enough to complete the project. }\end{array}$ & 100 & 1.00 & 5.00 & 4.4900 & .85865 \\
\hline $\begin{array}{l}\text { Budget management is very } \\
\text { important in ICT projects as it can } \\
\text { determine the level of success or } \\
\text { failure in the project. }\end{array}$ & 100 & 1.00 & 5.00 & 4.2300 & 1.18794 \\
\hline $\begin{array}{l}\text { An ICT project is considered a } \\
\text { success if completed in line with the } \\
\text { laid down specifications }\end{array}$ & 100 & 1.00 & 5.00 & 4.0200 & 1.26315 \\
\hline $\begin{array}{l}\text { An ICT project is considered a } \\
\text { failure if not completed in line with } \\
\text { the laid down specifications }\end{array}$ & 100 & 1.00 & 5.00 & 4.2200 & 1.05006 \\
\hline $\begin{array}{l}\text { Undertaking projects within } \\
\text { specification is very important in } \\
\text { ICT projects as it can determine the } \\
\text { level of success or failure in the } \\
\text { project. }\end{array}$ & 100 & 1.00 & 5.00 & 4.0200 & 1.29474 \\
\hline $\begin{array}{l}\text { A successful ICT project will make } \\
\text { the management happy while a } \\
\text { failed ICT project will make the } \\
\text { management sad. }\end{array}$ & 100 & 1.00 & 5.00 & 4.4900 & .85865 \\
\hline $\begin{array}{l}\text { A successful ICT project will make } \\
\text { the project team happy while a } \\
\text { failed ICT project will make the } \\
\text { project team sad. }\end{array}$ & 100 & 1.00 & 5.00 & 4.2300 & 1.18794 \\
\hline $\begin{array}{l}\text { A successful ICT project will make } \\
\text { the customers happy while a failed } \\
\text { ICT project will make the } \\
\text { customers sad. }\end{array}$ & 100 & 1.00 & 5.00 & 4.0200 & 1.26315 \\
\hline $\begin{array}{l}\text { Budget management is very } \\
\text { important in ICT projects as it can } \\
\text { determine the level of success or } \\
\text { failure in the project. }\end{array}$ & 100 & 1.00 & 5.00 & 4.2200 & 1.05006 \\
\hline Valid N (listwise) & 100 & & & & \\
\hline
\end{tabular}


From the descriptive statistics of gathered data above, it can be seen that none of the questionnaire is missing with respect to data being gathered as the entire questionnaire contained 100 responses as is in line with the total of 100 respondents in the study. The implication is that this research can as such be considered valid because the gathered data were computed for analysis and none of the gathered data is missing.

\section{Reliability}

It is important to compute the reliability of data gathered for research analysis in order to support further prove on the overall importance of the research being conducted. Lee Cronbach developed the Cronbach's Alpha in 1951 as a tool for measuring the internal consistence of gathered data. This tool is also used in this research to measure the reliability of gathered data and the findings from such measurement are as illustrated below.

Table 3.2: Case Processing Summary

\begin{tabular}{|ll|l|l|}
\hline & & $\mathrm{N}$ & $\%$ \\
\hline Cases & Valid & 100 & 100.0 \\
& Excluded $^{\mathrm{a}}$ & 0 & .0 \\
& Total & 100 & 100.0 \\
\hline
\end{tabular}

Table3.3: ReliabilityStatistics

\begin{tabular}{|l|l|}
\hline Cronbach's Alpha & N of Items \\
\hline .498 & 23 \\
\hline
\end{tabular}

The indication from the above table 3.3 as compared with the standards set by the cronbach analysis is that the table is poor in terms of reliability. In any case, this doesn't make the research void in the sense that a number of factors must be considered. The first of such is that the obtained figure of 0.498 can actually be approximated to 0.50 , which will easily meet the set standards and make the data reliable. Besides that, the validity of data has been significant in terms of reducing any doubts that might be related to gathered data because it can be seen from the validity analysis that all the gathered data were computed exactly as they were obtained and no data is missing from the analysis, which means that the data can be considered to be reliable.

\section{Methodology and Data Collection Problem}

Time - just as it is an issue in ICT project management, time play a significant role in the overall data gathering and analysis. This is because there was lesser time for the data to be gathered as it ended up that the proposed approach couldn't be easily followed. During the period of data gathering, some staffs were on leave while some students were not in school, which meant that the researcher had to allocate a different time for these staffs and students to be allowed to participant in the research.

Questionnaire design - another issue which was of lesser significance than the time issue discussed above is that of designing the questionnaire. The difficulty with this is that it was not easy defining the questions to be asked and how they will be asked. This is based on the understanding gathered in the review of literature in which it was made known that different individuals view the factors differently.

\section{Introduction}

Earlier on, it was noticed that the focus of the third chapter is on presenting how the research was conducted and validating the data gathered as well as measuring the reliability of gathered data. Following such success, this chapter will now focus on presenting an empirical analysis of the data gathered. The data analysis will however be divided into two sections, with this chapter focusing on the empirical analysis of the respondents data, while the chapter five will focus on the analyses of the data as loaded into the questionnaire. 
Figure 4.1: Employment status

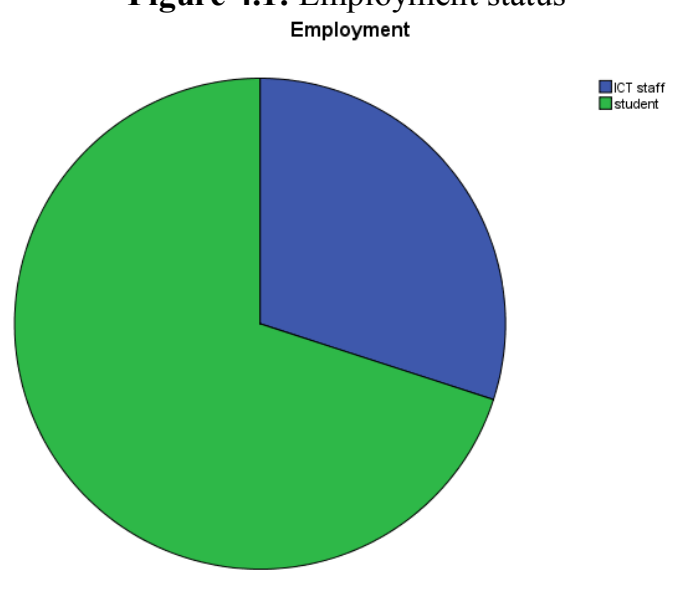

It is clear from the above figure 4.1 that majority of the respondents are students. Basically, this is correct as can be linked to the discussion presented in the methodology in which it was made known that the data will be gathered in Stanford College (amongst ICT students and staffs) and other ICT firms across Selangor.

Figure 4.2: Gender of Respondents

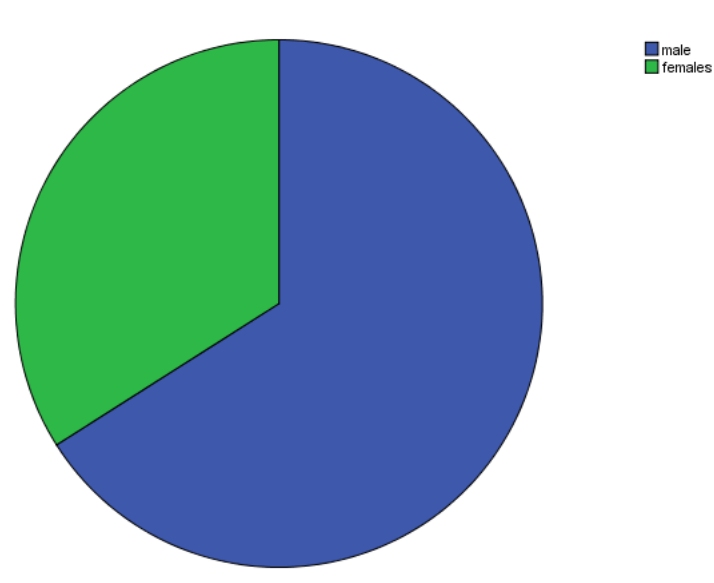

Following the previous analysis of the employment status of respondents is the understanding of how they fall in terms of their gender and it can be see that male respondents clearly represent the highest of the overall response. This is very common even in the ICT classes as there are more male students than female students and this could be a clear indication of gender differences in the field which presents a new area for further research.

Figure 4.3: Age of respondents

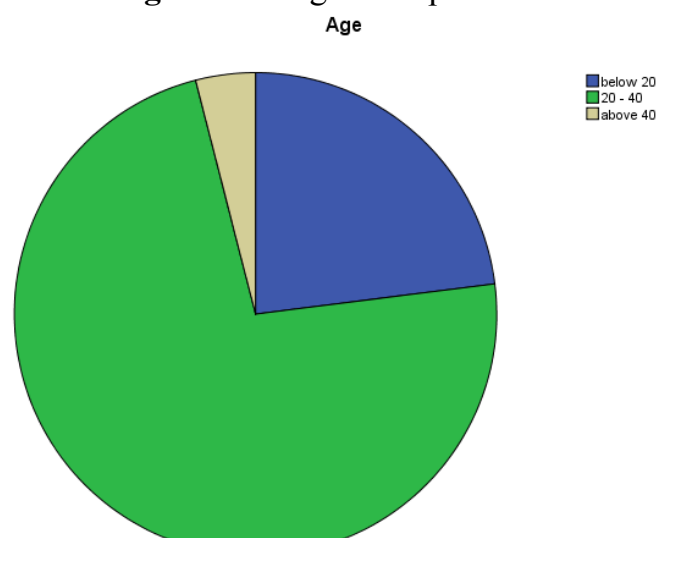


One variable that is very common in primary research is that of the age of respondents and the indication shown above is that most of the respondents fall between the ages of 20-40 followed by those below 20 years old. This is very much understandable on the account that they fall in working class age. As such, this also goes a long way to further validate the data gathered.

Figure 4.4: Type of ICT company respondents work for What type of ICT Company do you work with?
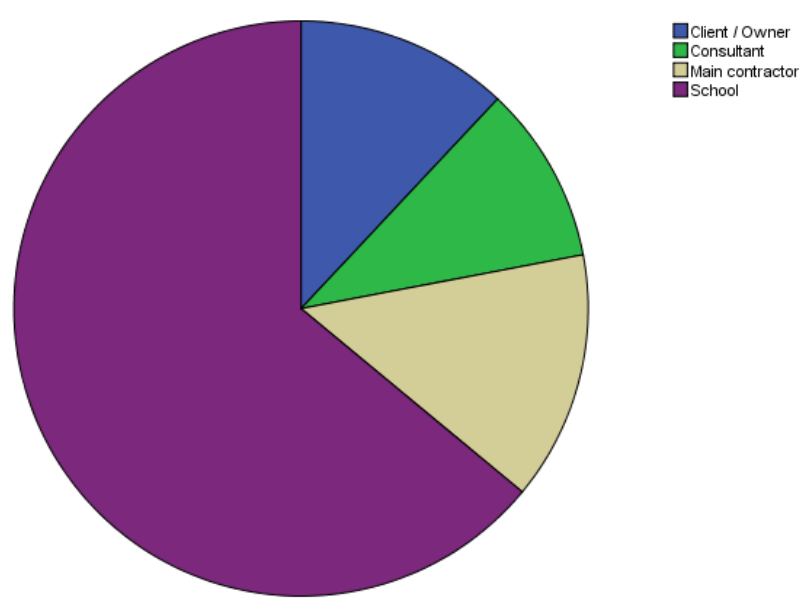

While it is clear that all the respondents are from ICT related field, there was no clear distinction of these respondents with respect to their job description or how they perform their ICT tasks. As such, the purpose of this research project is to present a clear understanding on that area by highlighting the areas these respondents work and it can be seen that most of them are from the education line. This is in line with earlier indications that most of the respondents are students. Besides those in the education line, other respondents also come from different segments of ICT industry and this is right for the quality of the research project as gathering similar data from different people in different segments of ICT industry will go a long way in proving the validity of the research project.

Figure 4.5: Role of respondents in the firm they work in / area of ICT studied for students Primary role in the company

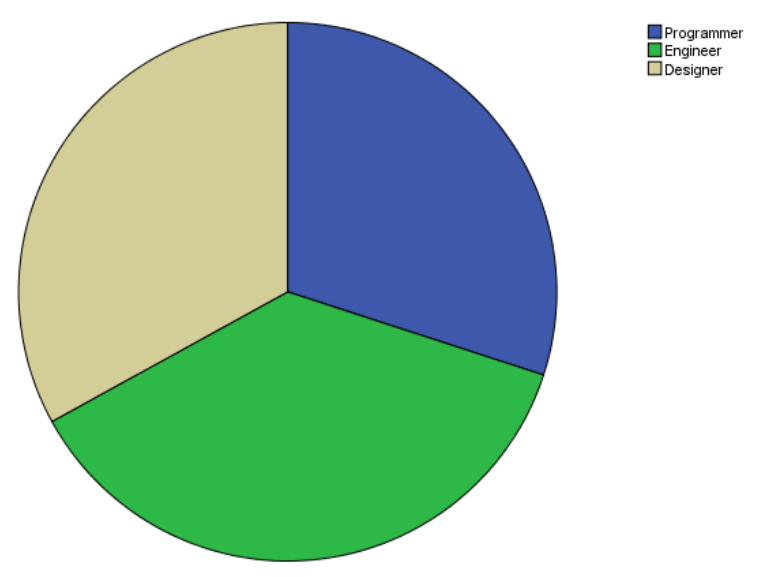

This section of the analysis presented a much clear understanding of the functions performed by the respondents. In terms of defining functions, it is meant to represent the jobs undertaken by staffs or area of ICT being studied by the students. The finding is of close similarities in terms of volume for deigning, programing and engineering. 
Figure 4.6:

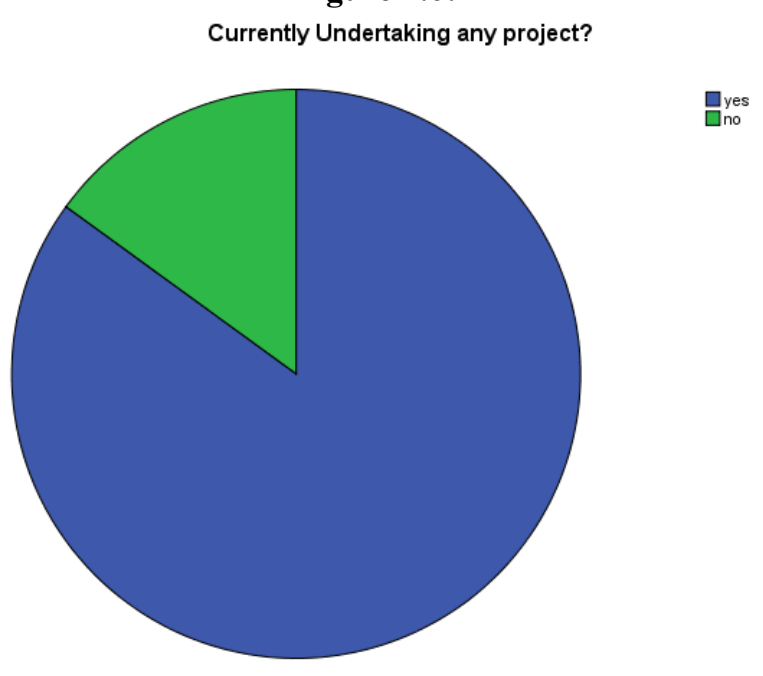

From the above illustration, it can be seen that majority of the respondents are currently undertaking ICT related project and this is very significant for this research because it would go a long way to understand their view about the factors being discussed with respect to their current ICT project.

From the above analyses, the right conditions have been created for ensuring that the finding form the research will be of the highest quality. This is because the respondents come from an ICT related field and they have experience with the factor have been discussed as well as well positioned to input the best of their knowledge because most of the respondents are currently undertaking ICT project.

\section{Introduction}

The focus of the previous chapter was to present an empirical analysis of the demographic and other variables about the respondents. In part with the discussion presented in chapter four above, this section will look to present an analysis of the finding from the cross-case data loaded into the questionnaire as it related to the factors that influences success or failure in ICT project management.

\section{Cross Case Analysis}

Table 5.1: What ICT proejct are you familiar with?

\begin{tabular}{|ll|l|l|l|l|}
\hline & Frequency & Percent & Valid Percent & Cumulative Percent \\
\hline Valid & student / education & 65 & 65.0 & 65.0 & 65.0 \\
& B2B & 12 & 12.0 & 12.0 & 77.0 \\
B2C & 16 & 16.0 & 16.0 & 93.0 \\
C2C & 7 & 7.0 & 7.0 & 100.0 \\
Total & 100 & 100.0 & 100.0 & \\
\hline
\end{tabular}

Prior to any definition, it was considered necessary to understand how familiar the respondents are with ICT projects and how long they have been doing such. The first table (5.1) above shows that most of the respondents are familiar with student and education related ICT program as they make up a total of $65 \%$ of the overall responds, which is very significant for the value of this paper. Besides the area of education, other respondents are well vast in the field of ICT program as it related to business-to-business and business-tocustomers; encompassing all areas of life and business segment. The value of such will be reflected later on in the discussions below.

Table 5.2: How long have you worked in ICT projects?

\begin{tabular}{|ll|l|l|l|l|}
\hline & Frequency & Percent & Valid Percent & Cumulative Percent \\
\hline Valid & 22 & 22.0 & 22.0 & 22.0 \\
& 30 & 30.0 & 30.0 & 52.0 \\
& 2 years & 13 & 13.0 & 13.0 & 65.0 \\
3 years & 35 & 35.0 & 35.0 & 100.0 \\
4 years or more & 35 & & &
\end{tabular}


Table 5.2: How long have you worked in ICT projects?

\begin{tabular}{|ll|l|l|l|l|}
\hline & Frequency & Percent & Valid Percent & Cumulative Percent \\
\hline Valid & 1 year & 22 & 22.0 & 22.0 & 22.0 \\
& 2 years & 30 & 30.0 & 30.0 & 52.0 \\
& 3 years & 13 & 13.0 & 13.0 & 65.0 \\
4 years or more & 35 & 35.0 & 35.0 & 100.0 \\
& Total & 100 & 100.0 & 100.0 & \\
\hline
\end{tabular}

While familiarity with ICT project is somewhat clear in the above table 5.1, it is also considered necessary to understand how long these respondents have been familiar with the project as it would serve as a direct measure of their competence in that area. From the above analysis, it can be seen that all the respondents have at least 1 year of experience with most of them making up in the area of 4 years of experiences (35\%) in ICT project, followed by those with 2 years of experiences $(30 \%)$ in ICT projects. The implication is that the overall quality of the paper is enhanced because such experiences give the respondents the right edge to contribute positively to the research.

Table 5.3: ICT Projects completed

\begin{tabular}{|ll|l|l|l|l|}
\hline & Frequency & Percent & Valid Percent & Cumulative Percent \\
\hline Valid & 1.00 & 11 & 11.0 & 11.0 & 11.0 \\
& 2.00 & 18 & 18.0 & 18.0 & 29.0 \\
& 3.00 & 16 & 16.0 & 16.0 & 45.0 \\
& 4 or more & 55 & 55.0 & 55.0 & 100.0 \\
& Total & 100 & 100.0 & 100.0 & \\
\hline
\end{tabular}

Still on the verge of understanding the level of experiences the respondents have, it can be seen that $55 \%$ of the respondents have completed at least 4 or more ICT project and this is very significant as it represents a high level of understanding in the field and familiarity with activities in the field - which puts them in a better position to answer questions that will be presented in this paper.

\section{Understanding the Influence of time on success or failure in ICT project}

Table 5.4: An ICT project is considered a success if it is completed within designated time.

\begin{tabular}{|ll|l|l|l|l|}
\hline & Frequency & Percent & Valid Percent & Cumulative Percent \\
\hline Valid & totally disagree & 7 & 7.0 & 7.0 & 7.0 \\
& Disagree & 5 & 5.0 & 5.0 & 12.0 \\
Neutral & 4 & 4.0 & 4.0 & 16.0 \\
Agree & 26 & 26.0 & 26.0 & 42.0 \\
totally agree & 58 & 58.0 & 58.0 & 100.0 \\
Total & 100 & 100.0 & 100.0 & \\
\hline
\end{tabular}

The first objective of this research is to illustrate the factors that influence success or failure in ICT project. From the table above (5.4), the question was loaded to understand what respondents think about completing a project on time being described as success in ICT project and a total of $84 \%$ of the respondents think that this is true. The indication then becomes that existing theories that state that projects completed on time is considered successful projects can then be supported from this finding. 
Table 5.5: An ICT project is considered a failure if it is not completed within designated time

\begin{tabular}{|ll|l|l|l|l|}
\hline & Frequency & Percent & Valid Percent & Cumulative Percent \\
\hline Valid & totally disagree & 9 & 9.0 & 9.0 & 9.0 \\
& Disagree & 6 & 6.0 & 6.0 & 15.0 \\
Neutral & 6 & 6.0 & 6.0 & 21.0 \\
Agree & 32 & 32.0 & 32.0 & 53.0 \\
totally agree & 47 & 47.0 & 47.0 & 100.0 \\
Total & 100 & 100.0 & 100.0 & \\
\hline
\end{tabular}

Following the first question of whether an ICT project that is completed on time can be described as a successful project is this question which is designed to understand what the respondents think about project that are not completed on time. From the above analysis, it can be seen that a total of $79 \%$ of the respondents thing think that such is true. It can easily be noticed that there is a $5 \%$ differences between the number of respondents that agree with this statement and those that agree with the finding in table 5.4 above. As such, this illustrates earlier notions that differences exist in terms of how people view success or failure in ICT project. The reason for such difference can be based on the understanding that while a project might not be completed on time, it can still be able to meet the needs it was designed for and as such it cannot be viewed as a total failure.

Table 5.6: Time management is very crucial in ICT project management because it can determine the level of success to be achieved from the project.

\begin{tabular}{|ll|l|l|l|l|}
\hline & Frequency & Percent & Valid Percent & Cumulative Percent \\
\hline Valid & totally disagree & 5 & 5.0 & 5.0 & 5.0 \\
& disagree & 4 & 4.0 & 4.0 & 9.0 \\
& neutral & 4 & 4.0 & 4.0 & 13.0 \\
agree & 38 & 38.0 & 38.0 & 51.0 \\
totally agree & 49 & 49.0 & 49.0 & 100.0 \\
Total & 100 & 100.0 & 100.0 & \\
\hline
\end{tabular}

Based on the understanding gained from the above tables that success in ICT project can be described as a case where the project is completed within stipulated timeframe, while failure can be described as a case where the project is not completed within the stipulated timeframe, it was deemed necessary to understand the influence of time management as a measure of success and/or failure. From the understanding above, it can be seen that $87 \%$ of the respondents agree that time management is very necessary in the success or failure of ICT project as it will ensure that the project is a success by being completed within the stipulated timeframe. As such, it is now clear that TIME is an influential factor in measuring the success or failure of a project.

Understanding the influence of "within budget "on success or failure of ICT project

Table 5.7: An ICT project is considered a success if completed within the stipulated budget

\begin{tabular}{|ll|l|l|l|l|}
\hline & Frequency & Percent & Valid Percent & Cumulative Percent \\
\hline Valid & totally disagree & 8 & 8.0 & 8.0 & 8.0 \\
& disagree & 9 & 9.0 & 9.0 & 17.0 \\
neutral & 7 & 7.0 & 7.0 & 24.0 \\
agree & 25 & 25.0 & 25.0 & 49.0 \\
totally agree & 51 & 51.0 & 51.0 & 100.0 \\
Total & 100 & 100.0 & 100.0 & \\
\hline
\end{tabular}

Just like the time factor, the purpose of this is to understand how a project can be deemed success or failure if completed within the provided budget. From the table (5.7) above, it is clear that the finding is not far from what was obtained in the case of time as $76 \%$ of the respondents agree that a project is considered a success if it is completed within the stipulated budget. 
Table 5.8: An ICT project is considered a failure if the stipulated budget is not enough to complete the project.

\begin{tabular}{|ll|l|l|l|l|}
\hline & Frequency & Percent & Valid Percent & Cumulative Percent \\
\hline Valid & totally disagree & 1 & 1.0 & 1.0 & 1.0 \\
& disagree & 6 & 6.0 & 6.0 & 7.0 \\
& agree & 29 & 29.0 & 29.0 & 36.0 \\
totally agree & 64 & 64.0 & 64.0 & 100.0 \\
Total & 100 & 100.0 & 100.0 & \\
\hline
\end{tabular}

Still on that same hand of understanding the influence of budget, it was made known in the above table 5.8 based on a total of $98 \%$ of the respondents agreeing that an ICT project is considered a failure is not completed within the budget stipulated in the planning stages of the project. This is in line with earlier notion that such case will expose the project to more risk.

Table 5.9: Budget management is very important in ICT projects as it can determine the level of success or failure in the project.

\begin{tabular}{|ll|l|l|l|l|}
\hline & Frequency & Percent & Valid Percent & Cumulative Percent \\
\hline Valid & totally disagree & 7 & 7.0 & 7.0 & 7.0 \\
& disagree & 5 & 5.0 & 5.0 & 12.0 \\
& neutral & 4 & 4.0 & 4.0 & 16.0 \\
agree & 26 & 26.0 & 26.0 & 42.0 \\
totally agree & 58 & 58.0 & 58.0 & 100.0 \\
Total & 100 & 100.0 & 100.0 & \\
\hline
\end{tabular}

Just as is obtainable from the case of time influence, the above able 5.9 shows that only $12 \%$ of the respondents disagree that budget management is very necessary in order to ensure the success of an ICT project. On that account, the total of $85 \%$ of respondents that considers such to be important is a reflection of the true value of budget management in determining the success or failure of a project.

Understanding the influence of specification on success or failure of ICT project

Table 5.10: An ICT project is considered a success if completed in line with the laid down specifications

\begin{tabular}{|ll|l|l|l|l|}
\hline & Frequency & Percent & Valid Percent & Cumulative Percent \\
\hline Valid & totally disagree & 9 & 9.0 & 9.0 & 9.0 \\
& disagree & 6 & 6.0 & 6.0 & 15.0 \\
neutral & 6 & 6.0 & 6.0 & 21.0 \\
agree & 32 & 32.0 & 32.0 & 53.0 \\
totally agree & 47 & 47.0 & 47.0 & 100.0 \\
Total & 100 & 100.0 & 100.0 & \\
\hline
\end{tabular}

Another factor that was loaded into the analysis is the understanding of how undertaking projects in designated specifications influences success or failure. From the understanding gained from the above analysis, it can be seen that $79 \%$ of the respondents agree that meeting the set specifications with respect to project is a direct measures of success because it is more like a guarantee that the project will be able to perform the purpose it was designed for. 
5.11 An ICT project is considered a failure if not completed in line with the laid down specifications

\begin{tabular}{|ll|l|l|l|l|}
\hline & Frequency & Percent & Valid Percent & Cumulative Percent \\
\hline Valid & totally disagree & 5 & 5.0 & 5.0 & 5.0 \\
& disagree & 4 & 4.0 & 4.0 & 9.0 \\
neutral & 4 & 4.0 & 4.0 & 13.0 \\
Agree & 38 & 38.0 & 38.0 & 51.0 \\
totally agree & 49 & 49.0 & 49.0 & 100.0 \\
Total & 100 & 100.0 & 100.0 & \\
\hline
\end{tabular}

The second notion just like in the two other factors discusses above is to understand how failure is influence in the project management process for ICT related projects by the lack of the project to meet set specifications. The understanding gained here is also similar with that gained from the above discussed factors in the sense that respondents generally think that the lack of project to meet set specifications means that the project has failed because this is the only way the project will be able to serve the purpose it was designed for.

Table 5.12: Undertaking projects within specification is very important in ICT projects as it can determine the level of success or failure in the project.

\begin{tabular}{|ll|l|l|l|l|}
\hline & Frequency & Percent & Valid Percent & Cumulative Percent \\
\hline Valid & totally disagree & 8 & 8.0 & 8.0 & 8.0 \\
& disagree & 9 & 9.0 & 9.0 & 17.0 \\
neutral & 7 & 7.0 & 7.0 & 24.0 \\
Agree & 25 & 25.0 & 25.0 & 49.0 \\
totally agree & 51 & 51.0 & 51.0 & 100.0 \\
Total & 100 & 100.0 & 100.0 & \\
\hline
\end{tabular}

Based on the understanding already related with respect to undertaking projects in such a way that it is based on specifications, it can easily be stated that specification is very significant in the project process. This is also heavily agreed upon by the respondents with $76 \%$ of then stating that such is true.

\section{Measuring the influences of successful or failed ICT project on stakeholders' happiness}

Table 5.13: A successful ICT project will make the management happy while a failed ICT project will make the management sad.

\begin{tabular}{|ll|l|l|l|l|}
\hline & Frequency & Percent & Valid Percent & Cumulative Percent \\
\hline Valid & totally disagree & 1 & 1.0 & 1.0 & 1.0 \\
& disagree & 6 & 6.0 & 6.0 & 7.0 \\
& Agree & 29 & 29.0 & 29.0 & 36.0 \\
totally agree & 64 & 64.0 & 64.0 & 100.0 \\
Total & 100 & 100.0 & 100.0 & \\
\hline
\end{tabular}

With the three main factors already handled in the above tables, it is now time to measure how project success influences happiness of the stakeholders. The first of such is to understand how it influences happiness with respect to the management and $98 \%$ of the respondents agree that such case will make the management happy while failure will make them sad. This is easily understandable because it is also a direct measure of their competence in the sense that success will showcase their ability to handle projects while failure will put doubts in their capabilities with respect to future projects. 
Table 5:14 A successful ICT project will make the project team happy while a failed ICT project will make the project team sad.

\begin{tabular}{|ll|l|l|l|l|}
\hline & Frequency & Percent & Valid Percent & Cumulative Percent \\
\hline Valid & totally disagree & 7 & 7.0 & 7.0 & 7.0 \\
& disagree & 5 & 5.0 & 5.0 & 12.0 \\
& neutral & 4 & 4.0 & 4.0 & 16.0 \\
agree & 26 & 26.0 & 26.0 & 42.0 \\
totally agree & 58 & 58.0 & 58.0 & 100.0 \\
Total & 100 & 100.0 & 100.0 & \\
\hline
\end{tabular}

Similar with the table 5.13 above, the respondents as contained in the table 5.14 are $(84 \%)$ agree that success of an ICT project will make the project team happy. Just like the management, this is a prove of competence and capability for the project team and as such they would be proud with success in project management as it related to ICT projects.

Table 5.15: A successful ICT project will make the customers happy while a failed ICT project will make the customers sad.

\begin{tabular}{|ll|l|l|l|l|}
\hline & Frequency & Percent & Valid Percent & Cumulative Percent \\
\hline Valid & totally disagree & 9 & 9.0 & 9.0 & 9.0 \\
& disagree & 6 & 6.0 & 6.0 & 15.0 \\
neutral & 6 & 6.0 & 6.0 & 21.0 \\
agree & 32 & 32.0 & 32.0 & 53.0 \\
totally agree & 47 & 47.0 & 47.0 & 100.0 \\
Total & 100 & 100.0 & 100.0 & \\
\hline
\end{tabular}

Still on the same view, it was noted that successful ICT projects will make customers happy and this is based on the understanding that such project will be able to meet their demands, which is the main reason why the project was developed.

Importance of budget management in ICT project success or failure

Table 5.16: Budget management is very important in ICT projects as it can determine the level of success or failure in the project.

\begin{tabular}{|ll|l|l|l|l|}
\hline & Frequency & Percent & Valid Percent & Cumulative Percent \\
\hline Valid & totally disagree & 5 & 5.0 & 5.0 & 5.0 \\
& Disagree & 4 & 4.0 & 4.0 & 9.0 \\
Neutral & 4 & 4.0 & 4.0 & 13.0 \\
Agree & 38 & 38.0 & 38.0 & 51.0 \\
totally agree & 49 & 49.0 & 49.0 & 100.0 \\
Total & 100 & 100.0 & 100.0 & \\
\hline
\end{tabular}

The final variable loaded into the question is that of understanding the influence of budget management in ICT project success. Budget is definitely important for any project management and ICT is no difference. On that account, it was deemed necessary to load it into this research. From the above table, it can be seen that $87 \%$ of the total respondents also agree with that notion.

Overall, the finding gathered from the above data analysis is similar with what already exist in literatures as discussed in the chapter 2 of this paper. The implication is such that project management is influences by a number of factors with TIME, SPECIFICATION, and BUDGET is very vital in project management. In line with that view, this paper can now be proved to be highly reliable as it in line with the finding from previous literature review. 


\section{Introduction}

So far, this research has been able to achieve the set objectives by following the set research guidelines as designed in the chapter 1 above. From that note, this chapter is focused on analysing the findings from the research. The finding will be as contained in the in the chapter 4 and chapter 5 of this research.

\section{Findings}

Earlier in the review of literature, it was noted that there are a number of factors that have been known in previous researches to influence the success or failure of ICT projects. These factors influence the ability of the project to be completed within stipulated time, with set specification and within approved budgets. Since there are differences in terms of people's view and measurement of success, then it was deemed right that success could influences happiness of the stakeholders and this was loaded into the questionnaire designed for this research.

The basic finding from the research that time, specification and budget is very important in project management with respect to ICT projects. The finding from the research is that a project is considered a success if it is completed within the specified time, set budget and specification. Additionally, it was also found that happiness is a great measure of project success, in the sense when project is successful, the stakeholders (management, project team and customers).

On that account, it can be stated that project success or failure is heavily influenced by the time frame, specification and within budget. The finding is in line with some of the existing literatures (especially those that highly time, specification and budget as having influence on the success or failure of ICT projects) and as such it can be viewed as a support to these literatures.

\section{Conclusion}

From the above discussions, it is now clear that success or failure is influenced by a number of factors. Some of these factors (such as time, specification and budget influence) have been studied earlier and proven in researches while other has not gained high attraction from modern students. Overall, the research can be considered a success because the finding are in line with earlier studies (for instance, if the ICT project is completed within time, budget and specification it can be considered a success) - which further validates the study and supports existing theories in these areas. In conclusion, it can now be stated that an ICT project should be completed within stipulated time, budget and specification in order to be considered as success.

\section{Suggestions For Future Work}

The factors review in this paper has been studied and proved in previous researches, with a new dimension developed in relation to happiness. The suggestion for further research is to further prove the relation of happiness with project success and develop other variables in relation to the terms.

\section{Contributions}

This study has been able to support existing theories in terms of time, budget and specification being of high influence in project success. This further proves existing theories and makes the research valuable.

\section{Comments}

While the research may have achieved its aims, it must be noted that conducting the research was not easy as it was filled with numerous setbacks. This is because the whole research involved a number of approaches that require high level of commitment in order for the research to be a success. In any case, this should not be considered a problem to the research because once the researcher is committed, success will be the outcome.

\section{References}

[1]. Pekka, S. (2008), “Increase ICT Project Success with Concrete Scope Management." Available at: http://www.compaid.com/caiinternet/ezine/forselius-scope.pdf [Accessed on: 29/07/2013].

[2]. Christensen, D.S. (1993, September) An Analysis of Cost Overruns on Defense Acquisition Contracts. Project Management Journal 3, 43-48.

[3]. DeMarco, T. "Mad About Measurement" essay in Why Does Software Cost So Much?, Dorset House Publishing, 1995.

[4]. Song, X.M., Montoya-Weiss, M.M. and Schmidt, J.B. Antecedents and Consequences of Cross-Functional Cooperation: A Comparison of R\&D, Manufacturing, and Marketing Per- spectives. Journal of Product Innovation Management, 14, 35-47. (1997).

[5]. Grönroos C. Relationship Marketing: Interaction, Dialogue and Value.Revista Europea de Dirección y Economía de la Empresa, 9 (3), 13-24. (2000).

[6]. Tzokas, N. and Saren, M. Building Relationship Platforms in Consumer Markets: A Value Chain Approach. Journal of Strategic Marketing, 5, 105-120. (1997).

[7]. Vorhies, D.W., Harker, M. and Rao, C.P. The Capabilities and Performance Advantages of Market-Driven Firms. European Journal of Marketing, 33 (11/12), 1171-1202. (1999). 
[8]. Dyer, J.H. and Nebeoka, K. Creating and Managing a High Performance Knowledge-Sharing Network: The Toyota Case.Strategic Management Journal, 21(3), 345-368. (2000).

[9]. Wei, Y.S. and Morgan, N.A. "Supportiveness of Organizational Climate, Market Orientation and New Product Performance in Chinese Firms", Journal of Product Innovation Management, 21 (novembre), 375-388. (2004).

[10]. Wright, J.N., 1997. Time and budget: the twin imperatives of a project sponsor International Journal of Project Management, vol. 15, pp. 181-186.

[11]. Turner, J.R., 1993. The handbook of project-based management, McGraw-Hill

[12]. Ingram, G., 2000. The way to enlightened project management, Project Manager Today.

[13]. Belassi, W., Tukel, O. I., 1996. A new framework for determining critical success/failure factors in projects, International Journal of Project Management, vol. 14., pp. 141-151.

[14]. Wateridge, J., 1998. How can IS/IT projects be measured for success?, International Journal of Project Management, vol. 16, pp. 59-63

[15]. Pinto, J.K., Slevin, D.P., 1989. Critical success factors in R\&D projects, Research technology management

[16]. Fowler, A., Walsh, M., 1999. Conflicting perceptions of success in an information systems project, International Journal of Project Management, vol. 17, pp. 1-10.

[17]. Wateridge, J., 1996. Delivering successful IS/IT projects: eight key elements from success criteria to review via appropiate management, methodologies and teams, $\mathrm{PhD}$. Henley management college, Brunel University.

\title{
APPENDICES
}

Appendix A: Questionnaire used in this research

\author{
Objectives \\ i. To understand the factors that influences success or failure in ICT projects. \\ ii. To understand the level of influence that these factors have in ICT projects. \\ iii. To understand if these factors can be reduced or enhanced.
}

\section{Instruction}

1. Answer ALL questions.

2. Fill _ in the box available based on the legend stated.

3. All information will be treated as confidential. It will be used ONLY for academic purpose.

4. All information will be on aggregated basis and no individual data will be published.

Note: Please fill up this form. The information given will be treated as highly confidential

\section{B. RESPONDENTS INFORMATION}

1. What type of ICT Company do you work with?

Client / Owner

Consultant

Main Contractor

School

2. What is your primary role in the company?

Programmer

Engineer

Designer

Project Manager

3. Are you currently undertaking any projects?

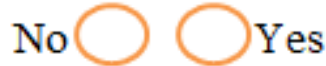

4. What kind of ICT project are you familiar with?

Student / Education system

B2B

$\mathrm{B} 2 \mathrm{C}$

$\mathrm{C} 2 \mathrm{C}$

5. How long have you worked in ICT projects?

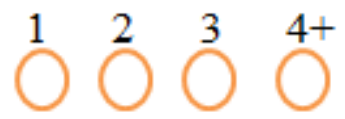


6. How long has your company been using ICT for business process?

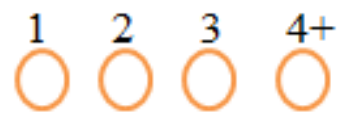

7. How many projects have you completed in ICT?

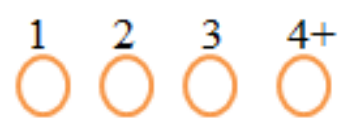

C. TIME INFLUENCE

8. An ICT project is considered a success if it is completed within designated time.

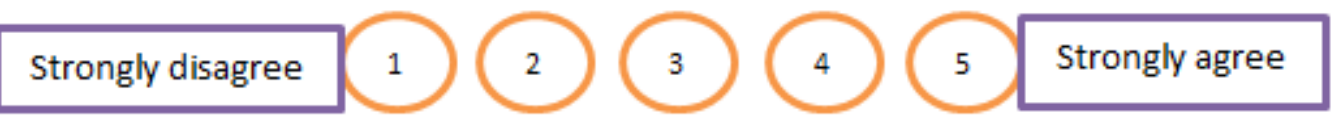

9. An ICT project is considered a failure if it is not completed within designated time

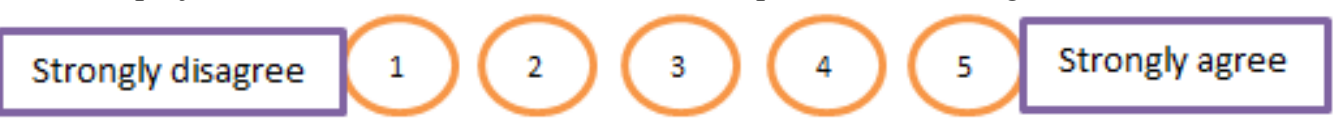

10. Time management is very crucial in ICT project management because it can determine the level of success to be achieved from the project.

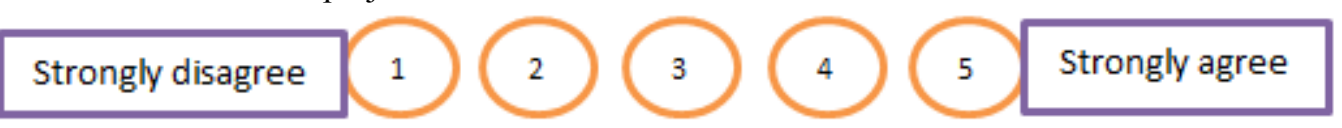

D. WITHIN BUDGET INFLUENCE

11. An ICT project is considered a success if completed within the stipulated budget

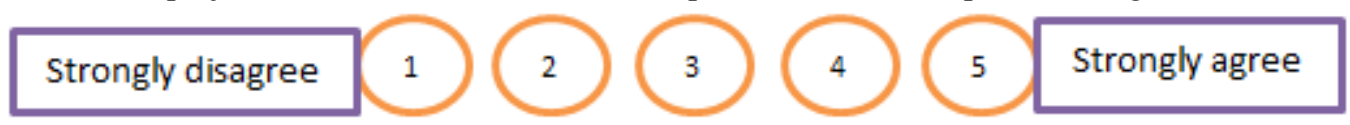

12. An ICT project is considered a failure if the stipulated budget is not enough to complete the project.

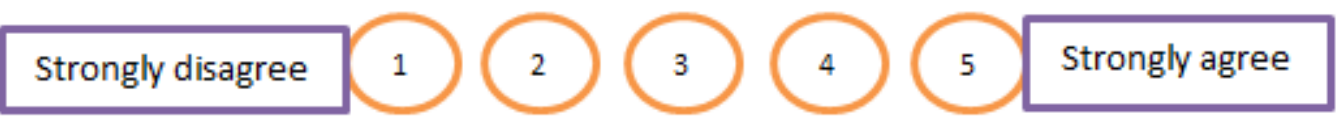

13. Budget management is very important in ICT projects as it can determine the level of success or failure in the project.

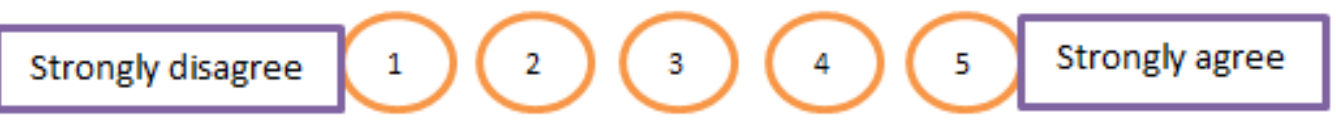

E. WITHIN SPECIFICATION INFLUENCE

14. An ICT project is considered a success if completed in line with the laid down specifications

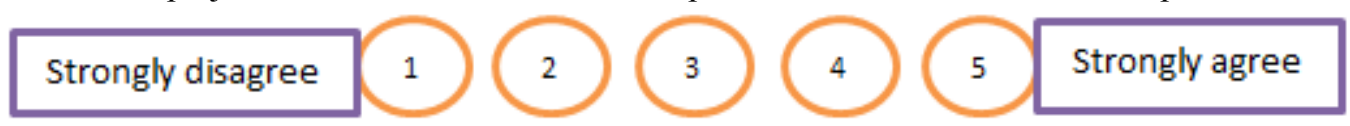

15. An ICT project is considered a failure if not completed in line with the laid down specifications

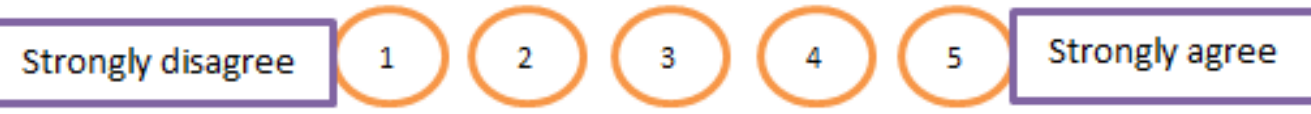

16. Undertaking projects within specification is very important in ICT projects as it can determine the level of success or failure in the project.

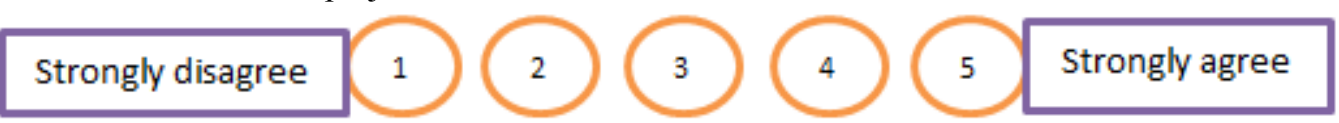

\section{F. STAKEHOLDERS HAPPINESS INFLUENCE}

17. A successful ICT project will make the management happy while a failed ICT project will make the management sad.

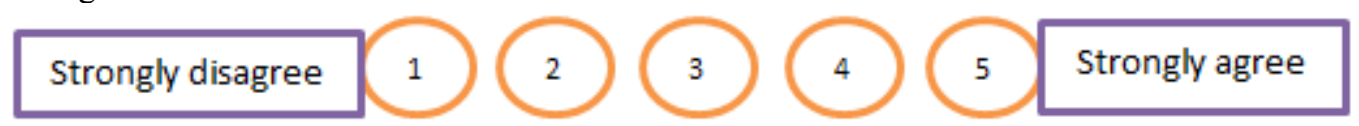

18. A successful ICT project will make the project team happy while a failed ICT project will make the project team sad. 


$\begin{array}{llll}\text { Strongly disagree } & 1 \\ & & & \end{array}$

19. A successful ICT project will make the customers happy while a failed ICT project will make the customers sad.

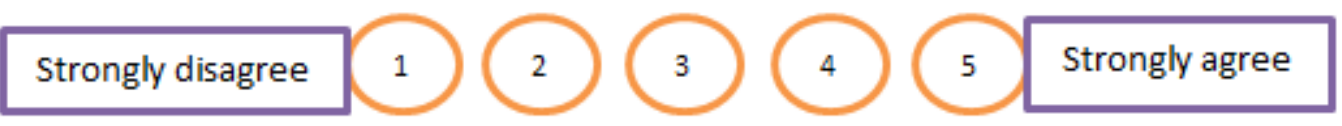

20. Budget management is very important in ICT projects as it can determine the level of success or failure in the project.

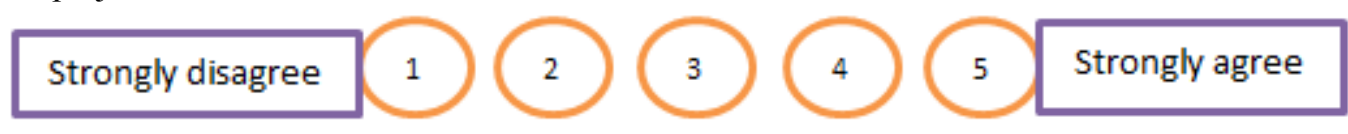

